\title{
Wentilactone A induces cell apoptosis by targeting AKR1C1 gene via the IGF-1R/IRS1/PI3K/AKT/Nrf2/FLIP/Caspase-3 signaling pathway in small cell lung cancer
}

\author{
WENLI JIANG ${ }^{1}$, LINGHONG MENG ${ }^{2}$, GUANGMING XU ${ }^{2}$, CUITING LV ${ }^{1}$, HONGLIANG WANG ${ }^{3}$, \\ HE TIAN $^{4}$, RUOHUA CHEN $^{5}$, BINGHUA JIAO ${ }^{1}$, BINGUI WANG $^{2}$ and CAIGUO HUANG ${ }^{1}$ \\ ${ }^{1}$ Department of Biochemistry and Molecular Biology, The Faculty of Basic Medical Science, \\ Second Military Medical University, Shanghai 200433; ${ }^{2}$ Laboratory of Marine Biology and Biotechnology, \\ Qingdao National Laboratory for Marine Science and Technology, Key Laboratory of Experimental Marine Biology, \\ Institute of Oceanology of The Chinese Academy of Sciences, Qingdao, Shandong 266071; \\ ${ }^{3}$ College of Pharmacy; ${ }^{4}$ Department of Pediatrics, Shanghai Hospital; ${ }^{5}$ Department of VIP Clinical, \\ Shanghai Hospital, Second Military Medical University, Shanghai 200433, P.R. China
}

Received November 23, 2016; Accepted March 26, 2018

DOI: $10.3892 / \mathrm{ol} .2018 .9486$

\begin{abstract}
Wentilactone A (WA), a marine-derived compound, inhibits proliferation of NCI-H446, as demonstrated by previous research; however, the anti-SCLC mechanism underlying WA was not fully investigated. The present study aimed to investigate the anti-SCLC mechanism underlying WA in vitro and in vivo. Cell Counting Kit- 8 was used to assay cell growth, flow cytometry was conducted to analyze cell apoptosis and nude mice xenografts were used to examine SCLC growth following WA treatment. Bioinformatics was used for verification of the target gene of WA. Reverse transcription-quantitative polymerase chain reaction and western blot were used to examine aldo-keto reductase family 1 member $\mathrm{C} 1$ (AKR1C1) mRNA and protein levels, and AKR1C1-associated proteins prior to and following WA treatment. Cell growth, apoptosis and growth of nude mice xenografts were assayed prior to and following transfection with AKR1C1 knockdown or overexpression carriers, respectively. It was determined that AKR1C1 was a target
\end{abstract}

Correspondence to: Dr Bingui Wang, Laboratory of Marine Biology and Biotechnology, Qingdao National Laboratory for Marine Science and Technology, Key Laboratory of Experimental Marine Biology, Institute of Oceanology of The Chinese Academy of Sciences, 7 Nanhai Road, Qingdao, Shandong 266071, P.R. China E-mail: wangbg@ms.qdio.ac.cn

Dr Caiguo Huang, Department of Biochemistry and Molecular Biology, The Faculty of Basic Medical Science, Second Military Medical University, 800 Xiangyin Road, Shanghai 200433, P.R. China

E-mail: huangcaig@hotmail.com

Key words: small cell lung cancer, growth, apoptosis, aldo-keto reductase family 1 member $\mathrm{C} 1$, insulin like growth factor 1 gene of WA. Decreased AKR1C1 expression and WA treatment promoted apoptosis in SCLC via the insulin like growth factor-1 receptor/insulin receptor substrate 1/phosphoinositide 3-kinase/AKT/nuclear factor-erythroid 2-associated factor 2/Fas-associated death domain-like interleukin-1-converting enzyme-like inhibitory protein/Caspase-3 pathway. WA attenuated the proliferation and induced the apoptosis of SCLC cells in vitro and in vivo by targeting the AKR1C1 gene. WA may be a novel AKR1C1-targeted drug candidate for the treatment of SCLC in the future.

\section{Introduction}

Lung cancer is a major cause of cancer-associated mortality, accounting for about $25 \%$ of all cancer mortalities globally in 2015 (1). Small cell lung cancer (SCLC), 15\% of all lung cancer cases, is an extremely aggressive malignancy with a tendency of fast growing rates, early distant metastases and poor prognosis (1). The 5-year survival rate of all patients with SCLC is $<10 \%$ (2). There are three kinds of SCLC treatment: The first is treatment with chemotherapeutic drugs (3). The second type involves targeted chemotherapy, which utilizes compounds that function in tumor cells with specific mutations prevent their proliferation, including gefitinib and imatinib (3). The third is immunotherapy (3). Although, SCLC is sensitive to chemotherapy and radiotherapy, there remains no effective way to fully treat SCLC (4). The majority of patients relapsed following first-line treatment (4).

The effect of available molecular targeted drug is not satisfactory $(3,5)$, therefore, it is of great significance to develop the molecule-targeted drugs with a good therapeutic effect but limited side effects.

Marine is rich in biological resources and has a complicated ecological environment (6,7). Marine nature products with diverse structures are an important source of drug discovery (8). For example, Wentilactone A (WA), as a small molecule marine-derived endophytic fungus, can inhibit the 
proliferation of SCLC cell line NCI-H446, as indicated by previous research (9); however, this previous study did not investigate the mechanism of WA inhibiting the proliferation of SCLC cells. The present study aimed to examine the anti-SCLC mechanism underlying WA in vitro and in vivo.

\section{Materials and methods}

Chemical compounds and reagents. The molecular weight of WA was $304 \mathrm{~g} / \mathrm{mol}$. The density of WA was $1.53 \mathrm{~g} / \mathrm{cm}^{3}$. The boiling point was $651.2^{\circ} \mathrm{C}$ at $760 \mathrm{mmHg}$. The WA used was supplied by the Institute of Oceanology of the Chinese Academy of Sciences, Qingdao, China, (chemical structure depicted in Fig. 1A, was dissolved in 100\% dimethyl sulfoxide (DMSO) (final concentration of WA was $1 \mathrm{mg} / \mathrm{ml}$ ), stored at $-20^{\circ} \mathrm{C}$ and diluted with culture medium (final concentration of WA was $10 \mu \mathrm{M}$ ) (RPMI-1640 with $10 \%$ fetal bovine serum (FBS) and penicillin and streptomycin $(10 \mu \mathrm{l} / \mathrm{ml})$. RPMI-1640, FBS, trypsin-EDTA, penicillin and streptomycin were purchased from Biowest (Nuaillé, France). DMSO was purchased from Bio-Light Biotech (Shanghai, China). The BCA protein assay kit, Annexin V-fluorescein isothiocyanate/propidium iodide (PI) apoptosis detection kit and Annexin V-APC Cell Apoptosis Analysis kit (with PI) were purchased from Tianjin Sungene Biotech Co., Ltd. (Beijing, China). Recombinant human insulin like growth factor-1 (IGF-1; 100-11) was purchased from PeproTech China (Suzhou, China). Anti-IGF-1 receptor (R) (ab182408; 1:1,000), anti-phosphorylated (p)IGF-1R (ab39398; 1:1,000), insulin receptor substrate 1 (IRS1) (ab40777; 1:1,000), anti-p-IRS1 (ab46800; 1:1,000), anti-Caspase-3 (ab13847; 1:1,000), anti-cleaved(c)-Caspase-3 (ab2302; 1:1,000), anti-aldo-keto reductase family 1 member C1 (AKR1C1)/AKR1C2 (ab96087; 1:1,000), anti-p-PI3K (ab182651; 1:1,000), anti-PI3K (ab1678; 1:1,000), anti-AKT (ab179463; 1:1,000) and anti-p-AKT (ab81283; 1:1,000) were purchased from Abcam (Cambridge, UK). Anti-Fas-associated death domain-like interleukin-1-converting enzyme-like inhibitory protein (FLIP) (ARG54328; 1:1,000) was purchased from Arigo Biolaboratories (Taiwan, R.O.C. China). Anti-cleaved (c)-FLIP (sc-8347, 1:1,000) was purchased from Santa Cruz Biotechnology, Inc. (Dallas, TX, USA). The chemiluminescence reagent was obtained from EMD Millipore (Billerica, MA, US). AKR1C1 gene expression lentivirus and AKR1C1 shRNA lentivirus were purchased from Shanghai Genepharma Technology Co., Ltd. (Shanghai, China). RevertAid First Stand cDNA Synthesis Kit was obtained from Thermo Fisher Scientific, Inc. (Waltham, MA, USA). TRIzol ${ }^{\circledR}$ reagent was purchased from Thermo Fisher Scientific, Inc.

Cell lines and culture. Human SCLC cell lines NCI-H446, NCI-H1688 and LTEP-sm cells were purchased from Tongpai Biological Technology Co., Ltd (Shanghai, China). NCI-H446, NCI-H1688 and LTEP-sm cells were cultured in RPMI-1640 containing 10\% FBS (Biological Industries, Cromwell, CT, USA), supplemented with $100 \mathrm{U} / \mathrm{ml}$ penicillin and $125 \mu \mathrm{g} / \mathrm{ml}$ streptomycin at $37^{\circ} \mathrm{C}$ in a $5 \% \mathrm{CO}_{2}$ incubator.

Cell proliferation assay. NCI-H446, NCI-H1688 and LTEP-sm cells were treated with $10 \mu \mathrm{M} \mathrm{WA}$ at 0,24 and $48 \mathrm{~h}$ at $37^{\circ} \mathrm{C}$. Cell growth was measured by Cell Counting Kit-8 assay (CCK-8; Dojindo Molecular Technologies, Inc., Kumamoto, Japan), according to the manufacturer's protocols. Experiments were repeated in triplicate.

Scratch assay. NCI-H446, NCI-H1688, LTEP-sm cells were placed on 6-well plates (Costar; Corning Incorporated, Corning, NY, USA) at a cell density of $5 \times 10^{5}$ cells/well in RPMI-1640 medium at $37^{\circ} \mathrm{C}$. At time $0 \mathrm{~h}$, a $200 \mu \mathrm{l}$ pipette tip was used to perform scratches in the confluent monolayer. At $48 \mathrm{~h}$, images were captured of scratches, using the marked plate bottom for orientation, with an Olympus 1X71 fluorescence microscope (x200), Olympus DP72 camera and DPController Software (Olympus Corporation, Tokyo, Japan). Measurements of scratch distance were completed by measuring the difference between the length of the initial scratch and the length of the scratch at $48 \mathrm{~h}$.

Cell apoptosis analysis. Cell apoptosis was determined by Annexin V-APC/PI apoptosis detection kit. Following treatment with WA $(10 \mu \mathrm{M})$ at $37^{\circ} \mathrm{C}$ for 0,24 or $48 \mathrm{~h}$, cells were collected and washed once with PBS and then suspended in $400 \mu 1$ binding buffer (supplied with the kit) for $30 \mathrm{sec}$. Following the addition of $4 \mu 1$ Annexin V-APC at room temperature, mixed and incubated in darkness for 10-15 min at room temperature, then resuspended cells were centrifuged at room temperature $(600 \mathrm{x} \mathrm{g}$ for $3 \mathrm{~min})$ to remove clear supernatant extract. Additionally, $4 \mu 1 \mathrm{PI}$ was added to every sample. Cells were re-suspended in PBS for flow cytometry analysis.

cDNA microarray analysis. Total RNA of NCI-H446 cell was extracted prior to or following a $48 \mathrm{~h} 10 \mu \mathrm{M}$ WA treatment at $37^{\circ} \mathrm{C}$ using the RNeasy mini kit (Qiagen $\mathrm{GmbH}$, Hilden, Germany). The microarray experiment was performed by Shanghai Genminix Informatics, Co., Ltd. (Shanghai, China) using Affymetrix Human Transcriptome Array chip (version 2.0), AGCC Flution Control software, GeneChip System 3000Dx version 2.0 microarray scanner (Affymetrix; Thermo Fisher Scientific, Inc.) and Genminix-Cloud Biotechnology Information platform (Genminix Informatics Co., Ltd.), according to the manufacturer's protocols.

Gene chip data analysis. GeneSifter program was used to analyze gene chip data, which extracts patterns of gene expression from Affymetrix gene expression data and uses Kyoto Encyclopedia of Genes and Genomes (KEGG) (http://www.kegg.jp/), Gene Ontology (GO) and Z-score reports to summarize the biological significance of a gene list $(10,11)$. All analyses were based on the GeneSifter software (version 5.0; Geospiza, Inc., Seattle, WA, USA). This program uses t-test and false discovery rate analysis to identify differentially expressed genes $(12,13)$. Standard selection criteria to further identify differentially expressed genes were as follows: $\mid \log 2$ ratios $\mid \geq 1$ and $\mathrm{P}<0.05(\log 2$ ratios $\geq 1.0$ represented up-regulated and $\log 2$ ratios $\leq-1.0$ represented downregulated). The association of expression profiles between the experimental and control groups was demonstrated by unsupervised hierarchical clustering analysis tree. Using the KEGG database, differently changed pathways were identified. Functional differences of the expressed genes were analyzed by $\mathrm{GO}$ and assigned into hierarchical categories. 
A

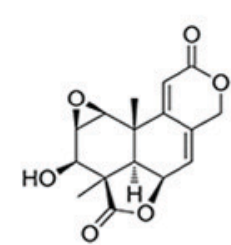

B

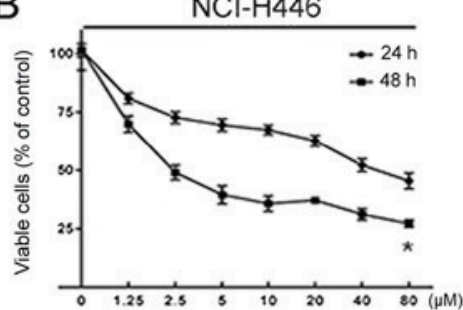

$\mathrm{NCl}-\mathrm{H} 1688$

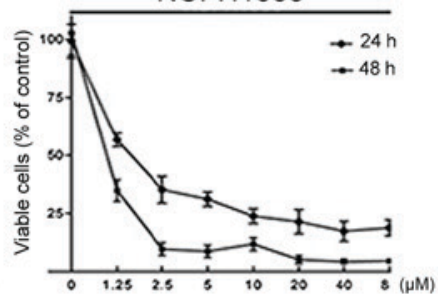

LTEP-sm

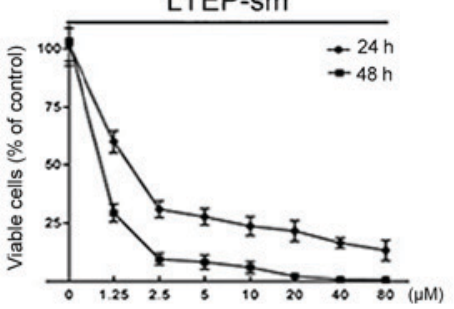

C
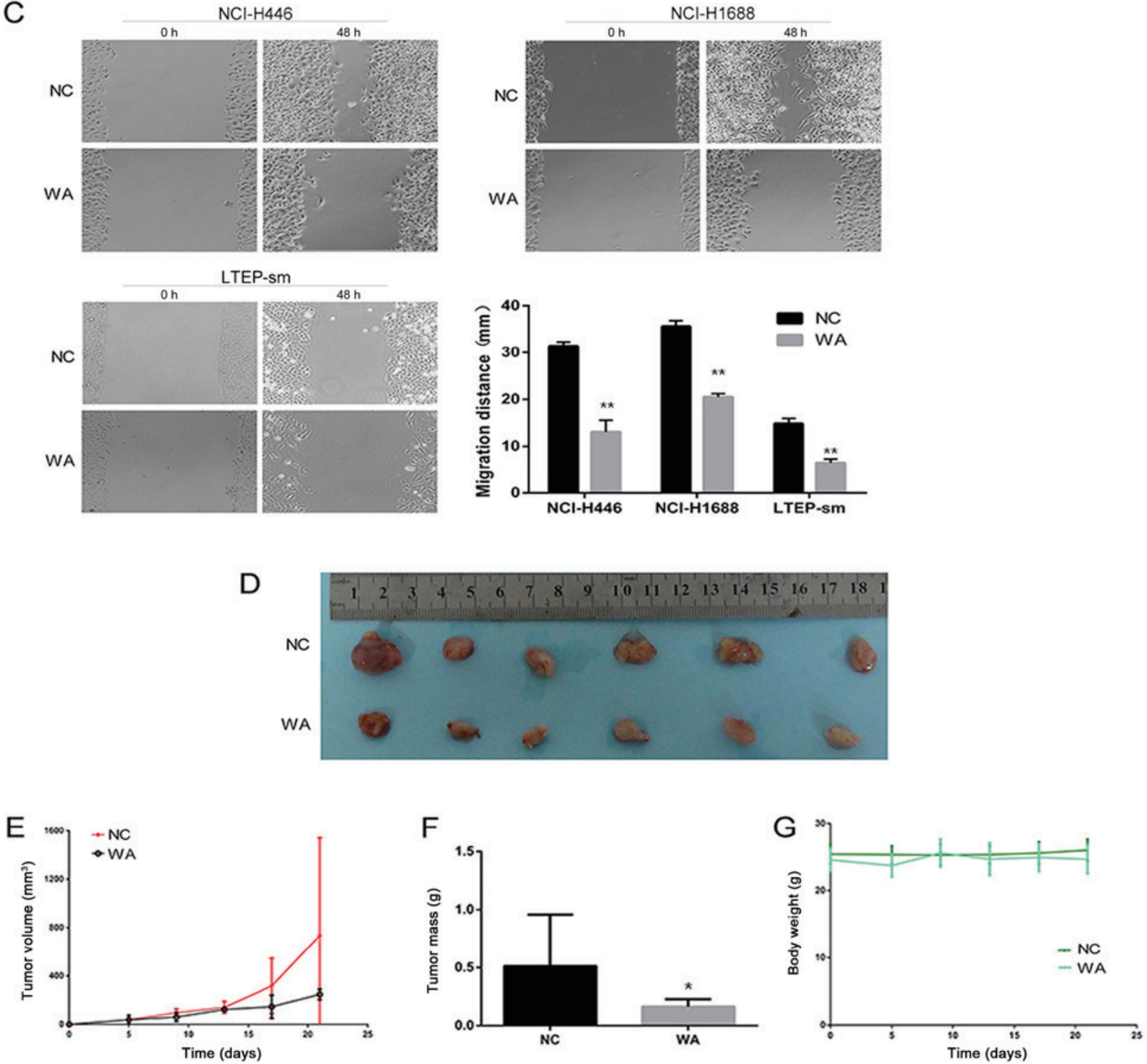

Figure 1. WA inhibited the proliferation of SCLC cells. (A) WA chemical structural formula. (B) The $\mathrm{IC}_{50}$ values of WA were detected by Cell Counting Kit-8 assay for SCLC cells following 24 and $48 \mathrm{~h}$. ${ }^{*} \mathrm{P}<0.05$. (C) Migration distance was detected by scratch assay. ${ }^{* *} \mathrm{P}<0.01$ vs. NC. (D) Tumors were harvested following 20 days. (E) The subcutaneous tumor volume growth curve of WA treatment was demonstrated. (F) The weight of the metastatic tumors in each group. ${ }^{*} \mathrm{P}<0.05$. (G) The body weight of the nude mice in each group. WA, Wentilactone A; NC, control group; SCLC, small cell lung cancer.

Reverse transcription-quantitative polymerase chain reaction $(R T-q P C R)(9,14)$. RT-qPCR was performed to determine the expressio of AKR1C1 mRNA in each cell sample, using GAPDH as an endogenous control for calibration. Total RNA was isolated using RNA Reagent (Tiangen Biotech Co., Ltd., Beijing, China), and genomic DNA was removed using Recombinant DNase I (Takara Biotechnology Inc., Dalian, Liaoning, China). RNA concentration and quality were measured by NanoDrop 2000 (Thermo Fisher Scientific,
Inc., Wilmington, DE, USA). Following analysis, samples with an OD 260/280 ratio from 1.9 to 2.1 were selected for further analysis. The primer sequences were designed using an online tool (http://bioinfo.ut.ee/primer3/), and the primers were purchased from BGI-Tech Solutions (Shanghai, China). The gene primer sequences were: AKR1C1, forward, CGTTGCCAGCTCATTGCTCTT, and reverse, TATGGC GGAAGCCAGCTTCAAT; GAPDH forward, GAGTCA ACGGATTTGGTCGT, and reverse, GACAAGCTTCCC 
GTTCTCAG. ABI 7500 real-time PCR system (Applied Biosystems; Thermo Fisher Scientific, Inc.) was used for the RT-qPCR reaction. The PCR solution $(20 \mu \mathrm{l})$ contained $10 \mu 1$ SYBR green (RR091A, Takara Biotechnology Ltd., Dalian, China), $0.5 \mu \mathrm{l}$ primer, $7 \mu \mathrm{lddH} 2 \mathrm{O}$ and $2.5 \mu \mathrm{l}$ cDNA. Thermal cycler conditions for RT-qPCR were as follows: Pre-denaturation at $95^{\circ} \mathrm{C}$ for $180 \mathrm{sec}$. Denaturation at $95^{\circ} \mathrm{C}$ for $10 \mathrm{sec}$. Annealing for $20 \mathrm{sec}$ at $60^{\circ} \mathrm{C}$. Extension at $72^{\circ} \mathrm{C}$ for $20 \mathrm{sec}$. Melting curve analysis was at $60^{\circ} \mathrm{C}$ for $6 \mathrm{sec}$. Using relative quantitative method and taking the control group as blank control, the relative transcriptional levels of mRNA of target genes were calculated using the $2^{-\Delta \Delta \mathrm{Cq}}$ method (15). This method was used for subsequent cell experiments. The experiment was repeated 3 times.

Transfection procedure. NCI-H446, NCI-H1688 and LTEP-sm cells were respectively transfected with AKR1C1 expressing vector (OE group), shRNA vector specific for AKR1C1 (KD group) and control green fluorescent protein (GFP) vectors (NC group). The negative control vector contained a GFP marker for cell tracking. The AKR1C1 expressing vector (pLenti-EF1 $\alpha$-GFP-puromycin-AKR1C1-Amp cDNA expression lentiviral vector) contained a green fluorescent protein marker. The shRNA vector specific for AKR1C1 vector was pGLV-H1-GFP-puromycin-shRNA-AKR1C1 vector. All were purchased from Shanghai GenePharma Co., Ltd. (Shanghai, China). Empty lentiviral vector was used as control. To further investigate the biological significance of the AKR1C1 gene in SCLC cells, NCI-H446, NCI-H1688 and LTEP-sm cells were transfected with AKR1C1 gene retroviral vector plasmid (OE group) or lentiviral vector carrying sh-AKR1C1 plasmid (KD group). Following $48 \mathrm{~h}$ transfection, fluorescence microscopy (x200) demonstrated the observed transfection efficiency. Following $72 \mathrm{~h}$ infection, the efficiency was validated by western blot analysis.

Cell proliferation assay following transfection. AKR1C1 overexpression or knockdown carrier transfected NCI-H446 cells were respectively plated in 96 -well plates at $4 \times 10^{3}$ cells/well. Following adherence overnight, cell viability was measured at $0,24,48$ and $72 \mathrm{~h}$ following WA treatment at $37^{\circ} \mathrm{C}$. Cell viability was determined by CCK-8 assay (Dojindo Molecular Technologies, Inc.), according to the manufacturer's protocols. The procedure also included adding reconstituted CCK- 8 in an amount equal to $10 \%$ of the RPMI-1640 medium volume and returning to the incubator at $37^{\circ} \mathrm{C}$ for $1 \mathrm{~h}$. Absorbance was measured at wavelength $450 \mathrm{~nm}$. Experiments were performed in triplicate, and three different experiments were performed under the same experimental conditions.

Western blot analysis. Prior to WA treatment for the indicated time perods $(0,12,24$ and 48 h), NCI-H446 and NCI-H1688 and LTEP-sm cells were seeded to six-well plates, and split by radio immunoprecipitation assay buffer containing phosphatase inhibitor, protease inhibitor and phenylmethanesulfonyl fluoride $(1: 1,000)$. Then the protein concentration was quantified by BCA protein assay kit. Using 10\% SDS-PAGE, the same amount of protein $(10 \mu \mathrm{g})$ was separated, transferred to nitrocellulose membranes and incubated with the aforementioned corresponding primary and secondary antibodies. Using the chemiluminescence reagent, the immunocomplexes were visualized and detected on images.

Nude mice xenograft model. The nude mice xenograft models were established by injection of $2 \times 10^{6}$ cells into the right armpit of 5-week old BALB/c male athymic mice (body weight, 18-22 g; National Rodent Laboratory Animal Resource, Shanghai, China). The mice were kept at room temperature, with a $12 \mathrm{~h}$ light/dark cycle with ad libitum access to food and water for 20 days. The mice were randomized into 6 groups (6 mice per group; total=36): Vehicle control (1\% DMSO); $10 \mathrm{mg} / \mathrm{kg}$ WA; cells transfected with AKR1C1 overexpression carriers, and 1\% DMSO; cells transfected with AKR1C1 overexpression carriers, and $10 \mathrm{mg} / \mathrm{kg}$ WA; cells transfected with AKR1C1 knockdown carriers, and 1\% DMSO; and cells transfected with AKR1C1 knockdown carriers, and $10 \mathrm{mg} / \mathrm{kg}$ WA when xenografts were palpable. Vehicle or drugs were administered intravenously every four days until sacrifice; where body weight and tumor size were measured and recorded simultaneously. Tumor size was measured using an electronic caliper, and the tumor volumes were calculated using the formula: (Length $\mathrm{x}$ width $\left.{ }^{2}\right) / 2$. Following 20 days, mice were sacrificed, and the tumors were collected, weighed and imaged. Tumor inhibition effect was calculated using the following equation: Tumor suppression $(\%)=(1-\mathrm{T} / \mathrm{C}) \times 100$, where $\mathrm{T}$ is the average tumor weight of the treated group and $\mathrm{C}$ is the average tumor weight of the control group. All protocols were approved by the University Animal Ethics Committee of the Second Military Medicine University.

Immunohistochemistry. All tumor xenograft tissues were fixed with $10 \%$ formalin for $24 \mathrm{~h}$ at room temperature and embedded in paraffin. Liquid paraffin wax was added to an iron mold and cooled slightly, then the tissue was placed in the paraffin wax and orientated correctly. Additional liquid paraffin was added, and the wax was frozen. The wax block was cut into $5 \mu \mathrm{m}$ sections each for 3 consecutive slices, slides were incubated with $8 \%$ goat serum (Dako; Agilent Technologies, Inc., Santa Clara, CA, USA; $250 \mu 1$ normal goat serum added to $5 \mathrm{ml} 50 \mathrm{mM}$ Tris-Cl) at $4^{\circ} \mathrm{C}$ for $2 \mathrm{~h}$ and incubated with $50 \mu 1$ the primary anti-AKR1C1 antibody at $4^{\circ} \mathrm{C}$ overnight. Sections were washed with PBS three times, each time for $5 \mathrm{~min}$. Subsequent to removing the PBS liquid, $50 \mu 1$ biotin-labeled secondary antibody (ab6788; Abcam; 1:500) was dropped onto each slice, which was then incubated at room temperature for $10 \mathrm{~min}$. All stained sections were examined under a light microscope (magnification, $\mathrm{x} 200$ ). The sections were stained and analyzed histologically according to the operating manual.

Statistical analysis. Statistical analysis was performed using SPSS 17.0 statistical software (SPSS, Inc., Chicago, IL, USA). All numerical results are expressed as the mean \pm standard deviation. Significant differences among groups were determined with a one-way ANOVA. When the differences were significant, a Student-Newman-Keuls test at a 5\% probability was conducted. $\mathrm{P}<0.05$ was considered to indicate a statistically significant difference. 
A
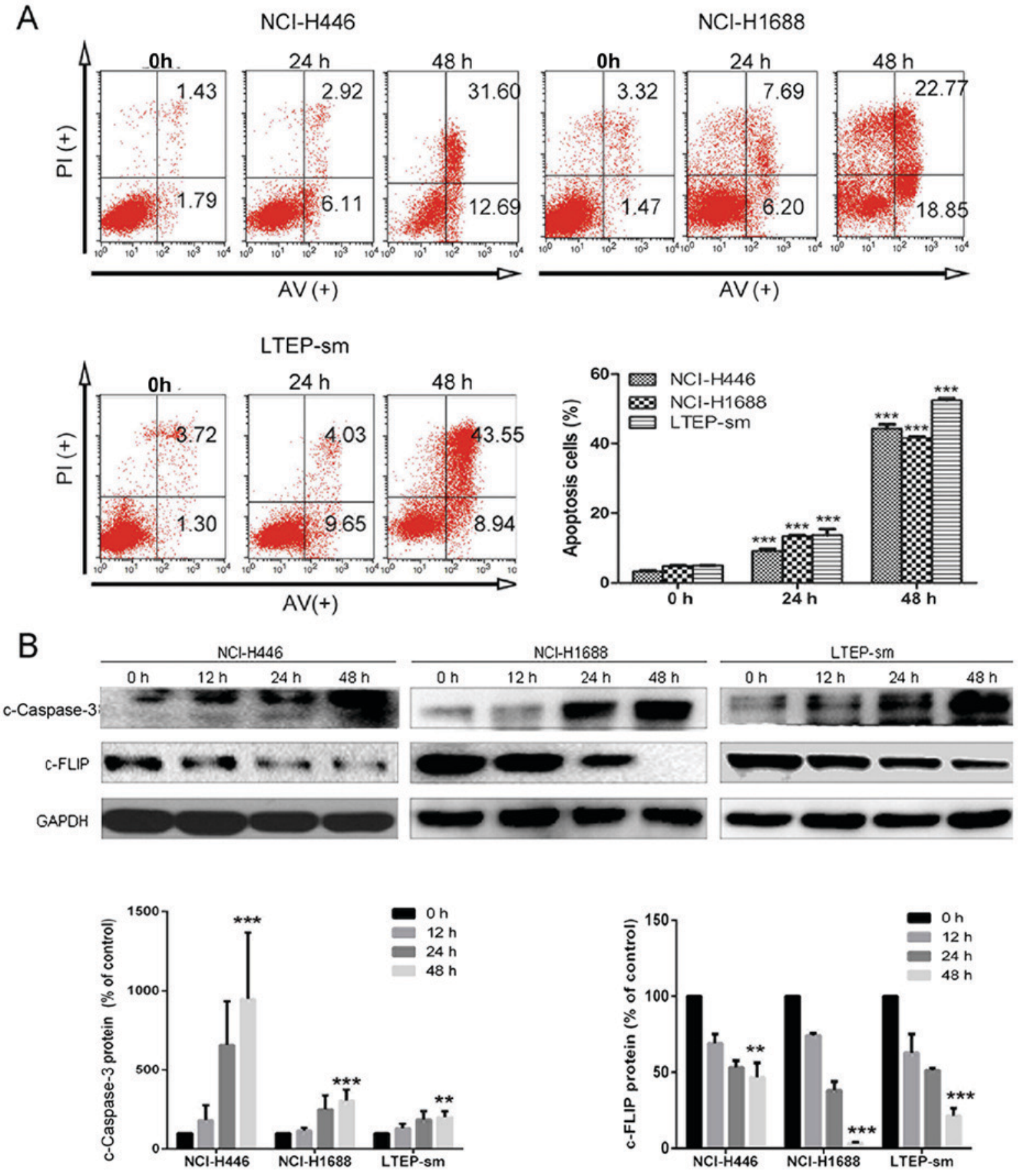

Figure 2. WA induced cell apoptosis of SCLC cells. (A) The apoptosis cells of SCLC were assessed via a flow cytometry assay. The number of cells undergoing apoptosis in the WA treatment group was significantly higher, compared with the $0 \mathrm{~h}$ group. ${ }^{* * *} \mathrm{P}<0.001 \mathrm{vs} .0 \mathrm{~h}$. (B) WA increased protein expression of c-Caspase-3 and attenuated protein expression of c-FLIP in SCLC cells. Protein expression was measured by western blot analysis. GAPDH was used as the reference protein. ${ }^{* * *} \mathrm{P}<0.001,{ }^{* *} \mathrm{P}<0.01$ vs. 0 h. WA, Wentilactone A; PI, propidium iodide; SCLC, small cell lung cancer; c-Caspase-3, cleaved-Caspase-3; c-FLIP, cleaved-Fas-associated death domain-like interleukin-1-converting enzyme-like inhibitory protein.

\section{Results}

WA significantly inhibits the proliferation of SCLC cells. As depicted in Fig. 1B, WA inhibited the proliferation of SCLC cells in a dose- and time-dependent manner. The $48 \mathrm{~h} \mathrm{IC}$ value of WA was $3.44 \pm 0.38 \mu \mathrm{mol} / 1$ for NCI-H446 cells The value was $0.41 \pm 0.18 \mu \mathrm{mol} / 1$ for NCI-H1688 cells and $0.57 \pm 0.10 \mu \mathrm{mol} / 1$ for LTEP-sm cells. The result of the scratch assay demonstrated that the migration ability of NCI-H446 cells was significantly decreased following 48 h WA treatment $(\mathrm{P}<0.01)$. Compared with the $48 \mathrm{~h}$ WA treatment group, the migration distance of NCI-H1688 cells was significantly decreased $(\mathrm{P}<0.01)$. Compared with the $48 \mathrm{~h}$ WA treatment group, the migration distance of LTEP-sm cells was decreased $(\mathrm{P}<0.01)$ (Fig. 1C). Further analysis on the inhibitory effect of WA in SCLC cells indicated that WA suppressed the growth 

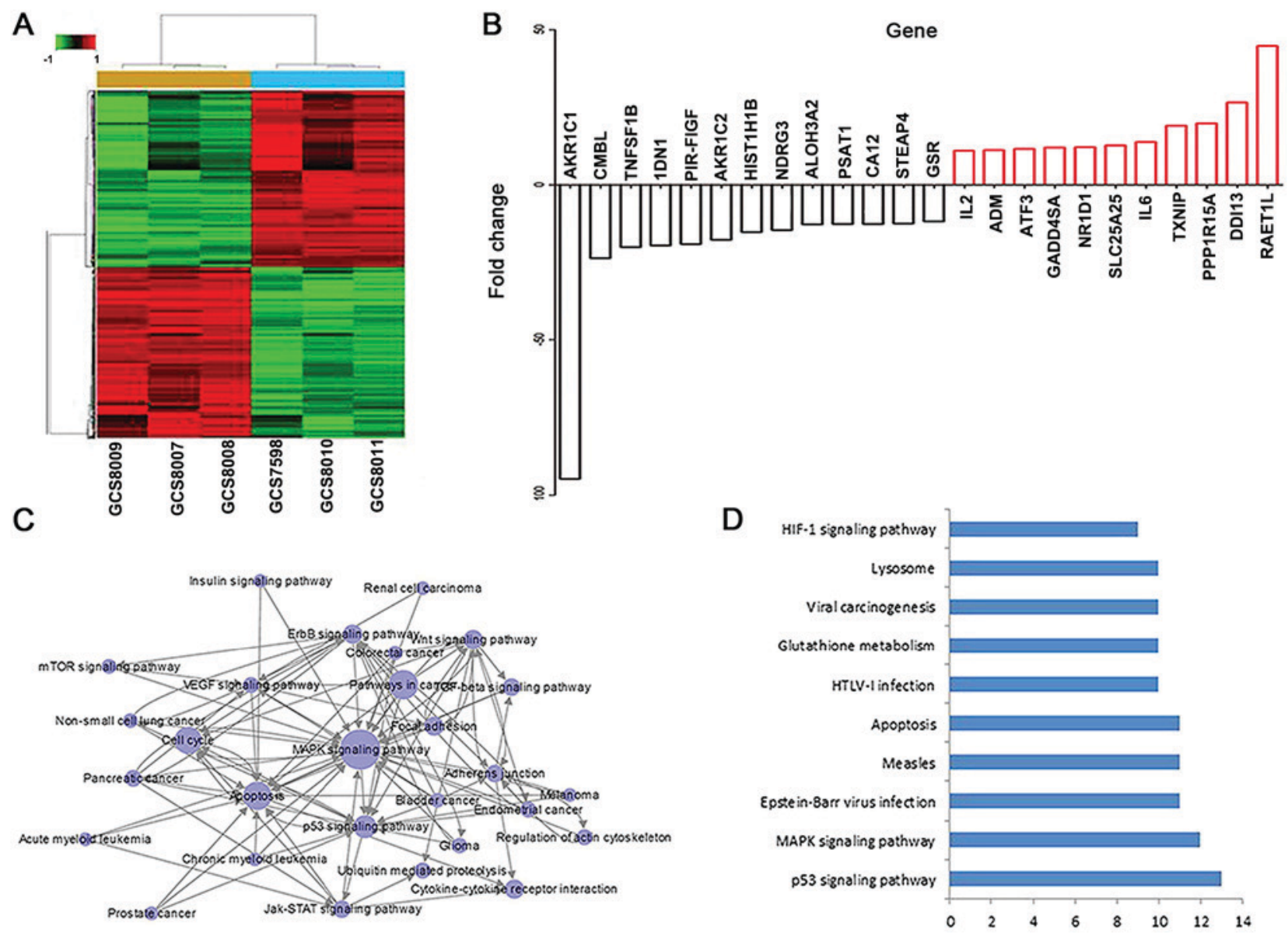

$\mathrm{E}$

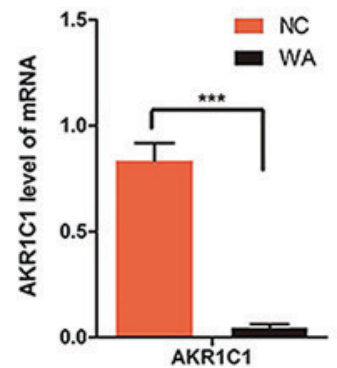

$\mathrm{F}$

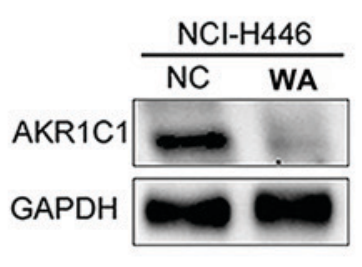

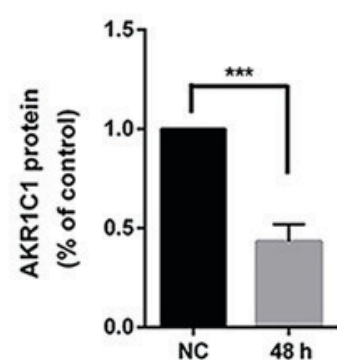

Figure 3. (A) Genesifter program heat map analysis. 17,873 genes were identified from the 60,000 transcripts that significantly changed over the experimental time course at 0 and 48 h. (B) Top 24 significantly changed genes. (C) Gene Ontology assay. (D) Pathway assay. (E) Reverse-transcription quantitative polymerase chain reaction changes in AKR1C1 gene expression, ${ }^{* * *} \mathrm{P}<0.001$ with a $95 \%$ confidential level. (F) Protein level was detected by western blot analysis. AKR1C1 was significantly reduced, ${ }^{* * *} \mathrm{P}<0.001$ with a $95 \%$ confidential level. AKR1C1, aldo-keto reductase family 1 member $\mathrm{C} 1$; MAPK, mitogen-activated protein kinase. HIF-1, hypoxia inducible factor 1; HTLV, human T-lymphotropic virus; WA, Wentilactone A; NC, control group.

of NCI-H446 cell xenograft tumor and no mice succumbed to causes other than interventional sacrifice (Fig. 1D-G). WA inhibited the growth of SCLC in vivo and in vitro.

WA inhibits the growth of SCLC via inducing apoptosis of tumor cells. The rates of cellular apoptosis were assessed in three SCLC cell lines NCI-H446, NCI-H1688, LTEP-sm by flow cytometry. The results demonstrated that the numbers of early and late apoptotic cells at $24-48 \mathrm{~h}$ post-treatment of WA in SCLC cells (Fig. 2A). Compared with the NC group of NCI-H446 cells, the numbers of early and late apoptotic cells in the WA treatment group was significantly increased $(\mathrm{P}<0.01)$. Compared with the NC group of NCI-H1688 cells, the numbers of early and late apoptotic cells following treatment of WA also significantly increased $(\mathrm{P}<0.01)$. Following treatment with WA, the numbers of early and late apoptotic LTEP-sm cells was significantly increased $(\mathrm{P}<0.01)$. Western blot results indicated that the apoptosis-associated protein levels of c-FLIP were decreased in WA treatment groups in NCI-H446 $(\mathrm{P}<0.01)$, NCI-H1688 $(\mathrm{P}<0.001)$ and LTEP-sm $(\mathrm{P}<0.001)$ cells, compared with the $\mathrm{NC}$ group; and the protein levels of c-Caspase-3 were increased in the WA treatment groups compared with the NC group $(\mathrm{P}<0.001$ for NCI-H446, $\mathrm{P}<0.001$ for NCI-H168 and $\mathrm{P}<0.01$ for LTEP-sm). These results indicated that WA induced cell apoptosis by regulating the FLIP-dependent apoptosis pathway. The apoptosis must 
A

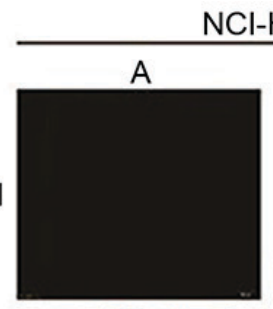

OE

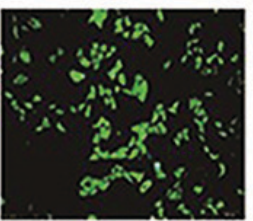

$\mathrm{NC}(\mathrm{OE})$

D

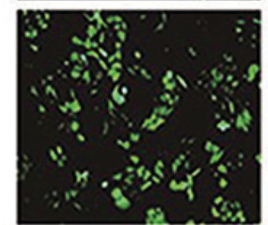

NC (KD)

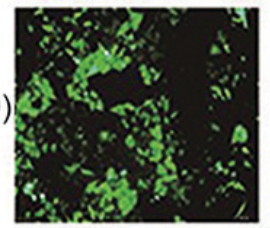

$\mathrm{NCl}-\mathrm{H} 1688$
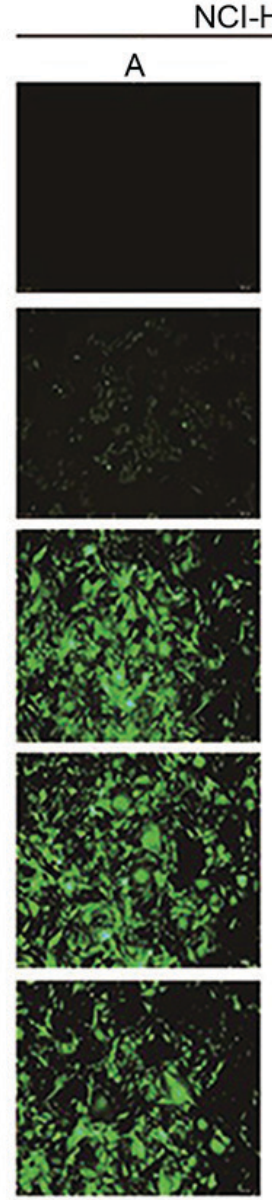

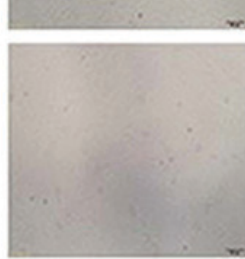

B
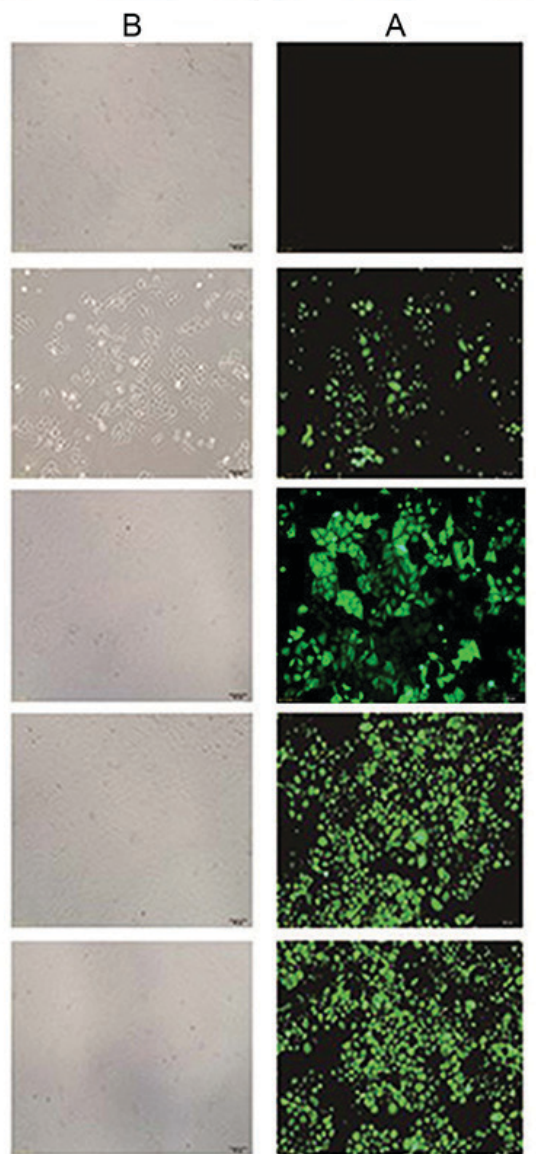

LTEPsm
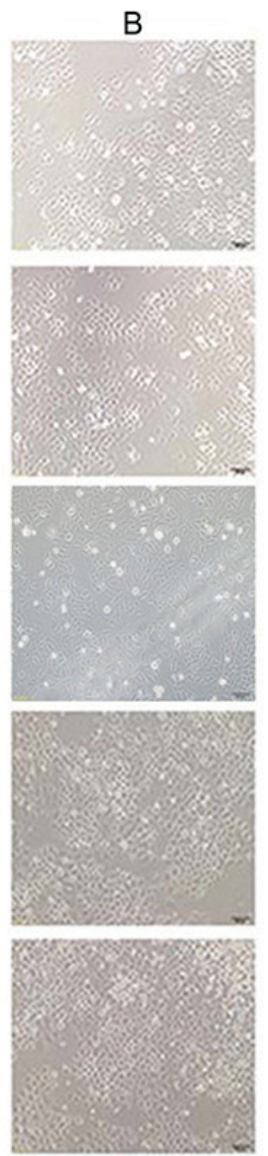

NC NC
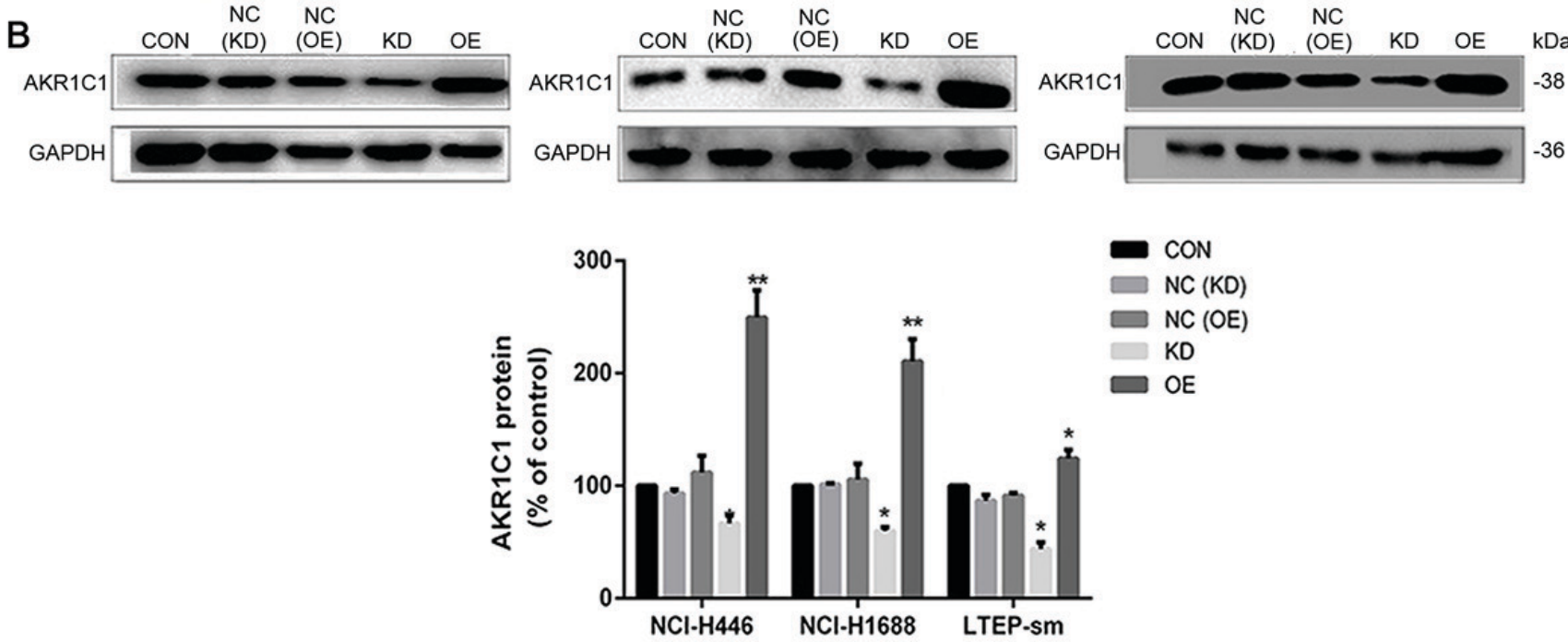

Figure 4. (A) Transfection efficiency was detected by fluorescence microscopy. (B) AKR1C1 protein level was detected by western blot analysis. AKR1C1 was significantly upregulated following transfection with $\mathrm{AKR} 1 \mathrm{Cl}$ gene retroviral vector plasmid, and downregulated following transfection with lentiviral vector carrying sh-AKR1C1 plasmid. GAPDH was used as a reference. ${ }^{*} \mathrm{P}<0.05$ and ${ }^{* *} \mathrm{P}<0.01$ vs. CON group. AKR1C1, aldo-keto reductase family 1 member $\mathrm{C} 1$; $\mathrm{NC}$, control group; KD, lentiviral vector carrying sh-AKR1C1 plasmid; OE, transfected with AKR1C1 gene retroviral vector plasmid; CON, control group.

be contributing factors leading to the growth attenuation in SCLC cells.

AKRICl as a target gene of WA. Bioinformatics analyses demonstrated that AKR1C1 may be a target gene of WA. According to the results of bioinformatics analysis, there are 17,873 differentially expressed genes during the progression of WA-mediated NCI-H446 cells. The association of expression profiles between the two groups was demonstrated by unsupervised hierarchical clustering analysis tree (Fig. 3A). The logarithm of the fluorescence intensity ratio was represented by fold change, and a $\log 2$ ratio $\geq 1.0$ or a $\log 2$ ratios $\leq-1.0$ means a two-fold change (Fig. 3B). These data indicated WA upregulated 10,560 genes and downregulated 7,313 genes. The AKR1C1 gene underwent the most significant change following WA treatment 
A

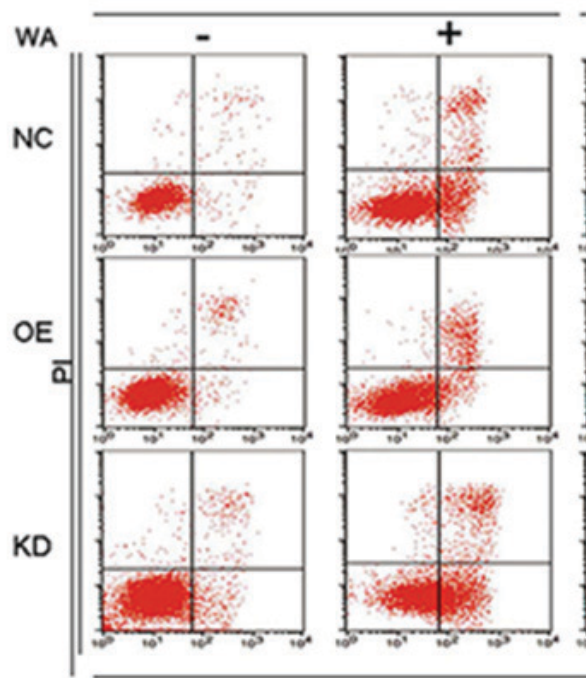

$\mathrm{NCl} \cdot \mathrm{H} 1688$

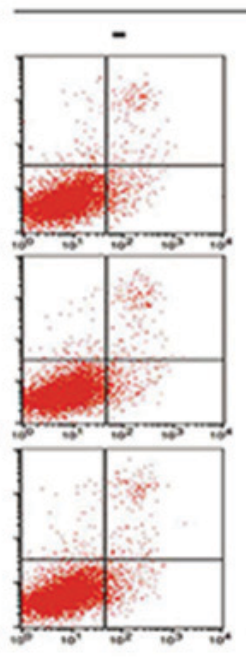

LTEPsm
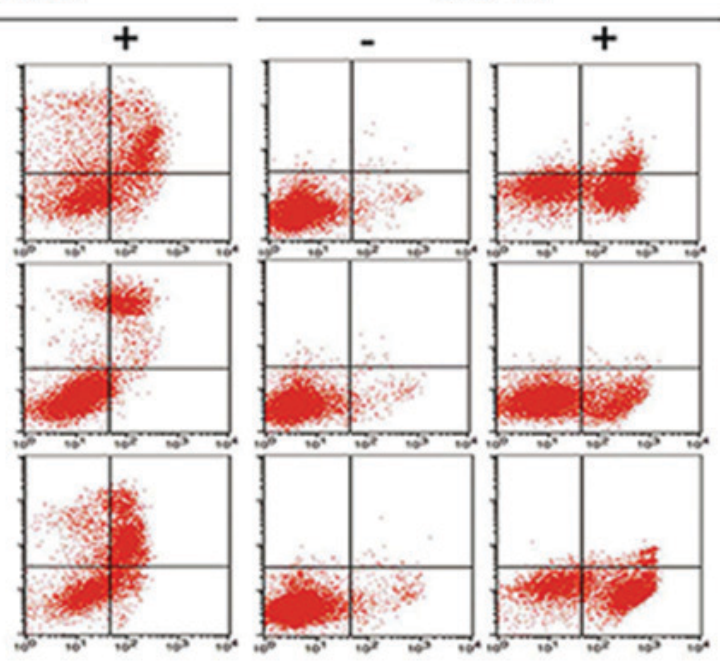
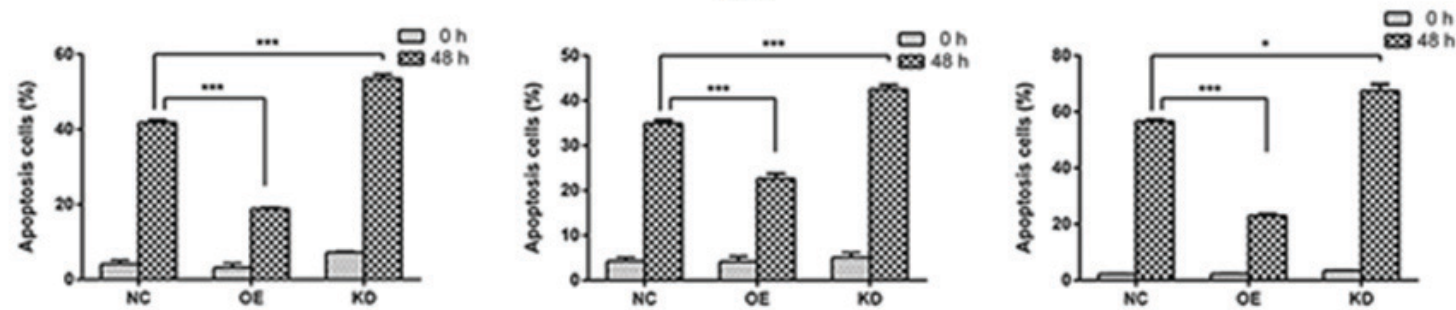

$B$

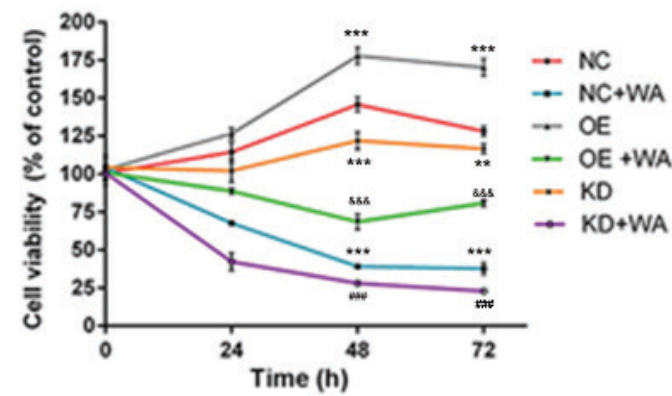

Figure 5. (A) WA treatment significantly induced SCLC cell apoptosis and overexpression of AKR1C1 gene reversed the pro-apoptotic effect of WA. There were six groups. OE group cells were infected with lentiviral vector LV5-AKR1C1; OE+WA group cells were infected with lentiviral vector LV5-AKR1C1 and WA treatment; NC group cells were non-WA-treatment; NC+WA group cells were WA treatment; KD group cells were infected with lentivirus particles carrying sh-AKR1C1; KD+ WA group cells were infected with lentivirus particles carrying sh-AKR1C1 and WA treatment. (B) Cell Counting Kit- 8 assay was utilized to evaluate cell proliferative capacity following transfection for $48 \mathrm{~h}, \mathrm{NC}+\mathrm{WA}$ group cells revealed a significant slower proliferation compared with the NC group. ${ }^{*} \mathrm{P}<0.05,{ }^{* *} \mathrm{P}<0.01$ and ${ }^{* * *} \mathrm{P}<0.001$. KD, lentiviral vector carrying sh-AKR1C1 plasmid compared with the KD group at the same time point,

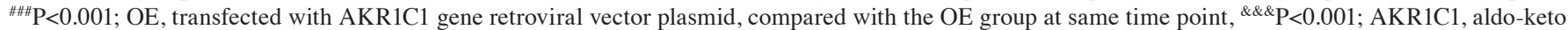
reductase family 1 member $\mathrm{C} 1$; NC, control group; WA, Wentilactone A; PI, propidium iodide; APC, allophycocyanin.

$(\mathrm{P}<0.001)$ (Fig. 3B). Pathway analysis demonstrated that the differentially expressed genes were mainly involved in $159 \mathrm{KEGG}$ classical pathways, particularly in the p53 signaling pathway (23 genes), mitogen-activated protein kinase signaling pathway (44 genes), apoptosis (23 genes), PI3K-AKT signaling pathway (40 genes), nuclear factor- $\kappa \mathrm{B}$ signaling pathway (17 genes), Janus kinase-signal transducer and activator of transcription signaling pathway (15 genes), vascular endothelial growth factor signaling pathway (16 genes) and insulin signaling pathway (18 genes; Fig. 3D). RT-qPCR analysis indicated that the mRNA expression level of gene AKR1C1 was notably decreased in the WA treatment NCI-H446 cells (Fig. 3E). Additionally, western blot analysis demonstrated that the protein expression level of AKR1C1 was notably decreased in the WA treatment NCI-H446 cells (Fig. 3F).

AKRIC1 attenuates SCLC cells apoptosis in vitro. Following $48 \mathrm{~h}$ transfection, fluorescence microscopy demonstrated that the observed transfection efficiency for NCI-H446, NCI-H1688 and LTEP-sm SCLC cell lines were all 99\% (Fig. 4A). Western blot analysis demonstrated the transfection efficiency (Fig. 4B). Additionally, the anti-apoptotic effect of AKR1C1 gene and pro-apoptotic effects of WA on SCLC cells were investigated by flow cytometry analysis. As depicted in Fig. 5A, compared with the NC group, the overexpression of AKR1C1 gene decreased the apoptosis of SCLC cells. Compared with NC group, WA treatment significantly induced 
A

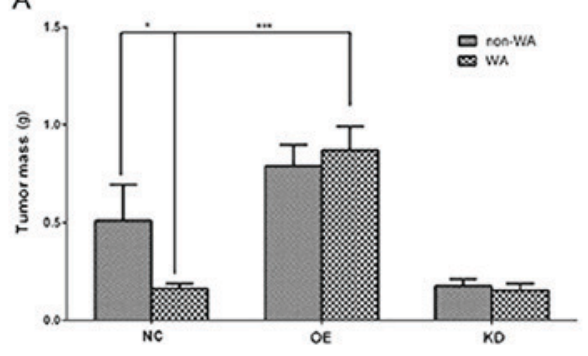

B

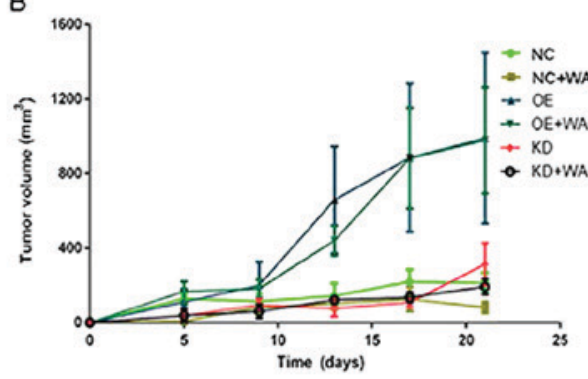

C

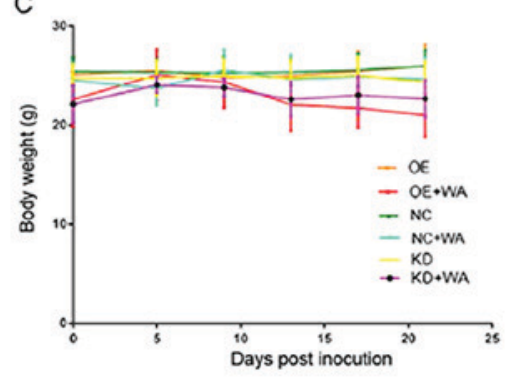

D

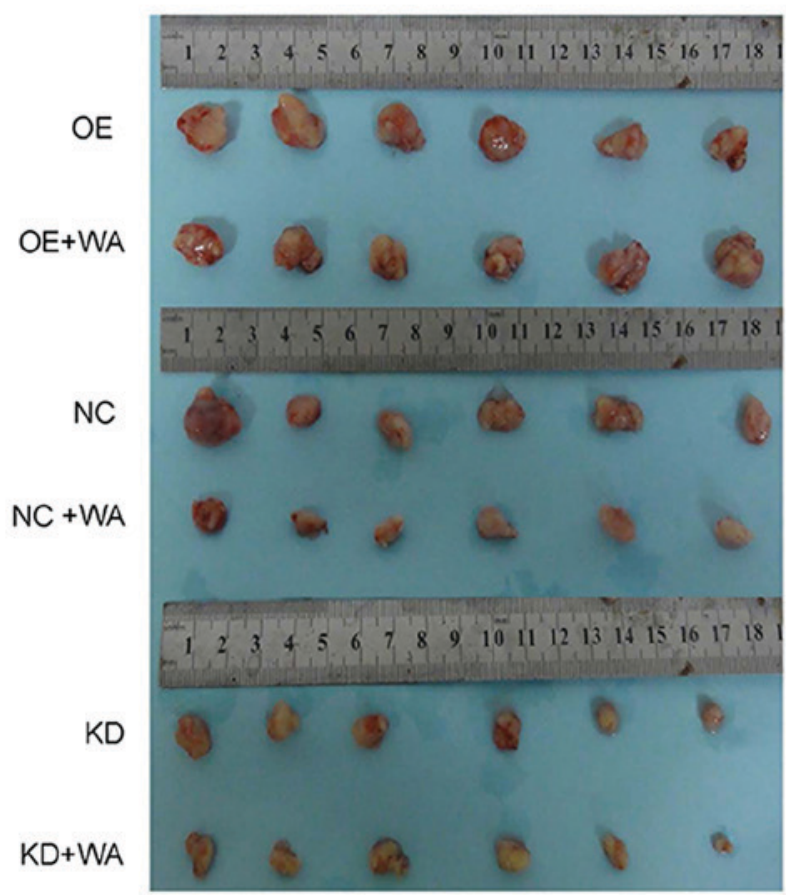

E

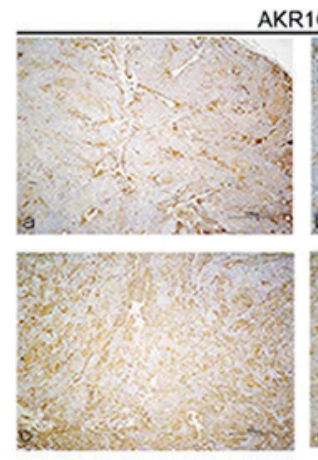

AKR1C1
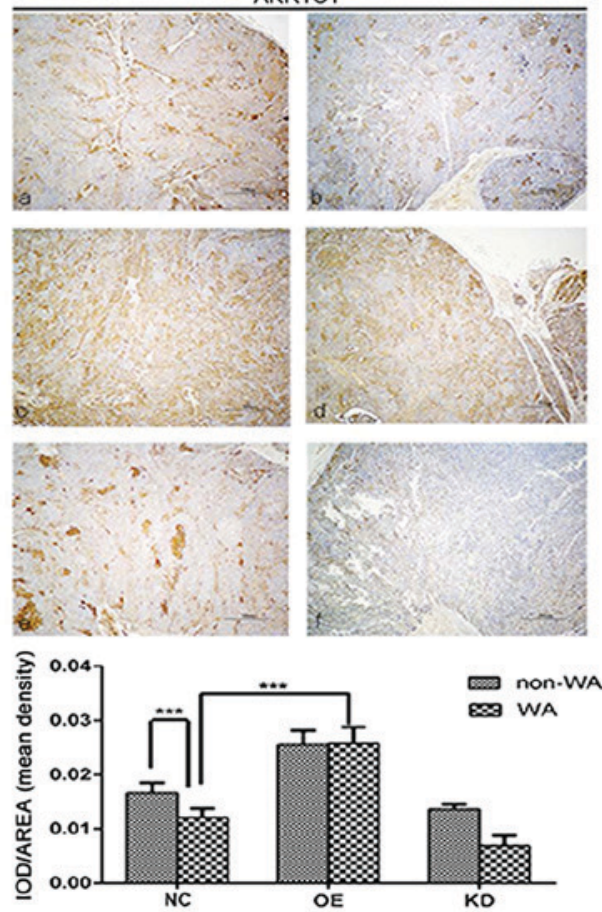

Figure 6. WA inhibited expression of AKR1C1 gene and tumor growth. There were six groups. OE group cells were infected with lentiviral vector LV5-AKR1C1; OE+WA group cells were infected with lentiviral vector LV5-AKR1C1 and WA treatment; NC group cells were non-WA-treatment; NC+WA group cells were WA treatment; KD group cells were infected with lentivirus particles carrying sh-AKR1C1; KD+WA group cells were infected with lentivirus particles carrying sh-AKR1C1 and WA treatment. (A) The weight of the metastatic tumors in each group. ${ }^{*} \mathrm{P}<0.05,{ }^{* * *} \mathrm{P}<0.001$. (B) The subcutaneous tumor volume growth curve of WA treatment was depicted. (C) The body weight of the nude mice in each group. (D) Tumors were harvested following 20 days. (E) Immunohistochemical staining of (a) $\mathrm{NC}$ group, (b) NC+WA group, (c) OE group, (d) OE+WA group, (e) KD group and (f) KD+WA group. *** $\mathrm{P}<0.001$. KD, lentiviral vector carrying sh-AKR1C1 plasmid; OE, transfected with AKR1C1 gene retroviral vector plasmid; AKR1C1, aldo-keto reductase family 1 member $\mathrm{C} 1$; NC, control group; WA, Wentilactone A; IOD/AREA, Integrated optical density per stained area.

SCLC cell apoptosis $(\mathrm{P}<0.001)$. Compared with the apoptosis rate $41.81 \pm 0.60 \%$ in $48 \mathrm{~h}$ WA-treated NC group NCI-H446 cells, the apoptosis rate was $18.86 \pm 0.23 \%$ in $48 \mathrm{~h}$ WA-treated OE group NCI-H446 cells and $53.59 \pm 1.05 \%$ in $48 \mathrm{~h}$ WA-treated KD group NCI-H446 cells. The aforementioned results indicated that WA enhanced cell apoptosis; however, overexpression of AKR1C1 reversed the effect of WA, and knockdown of AKR1C1 promoted the effect of WA in SCLC cells. As depicted in Fig. 5B, the CCK-8 array demonstrated that the knockdown of AKR1C1 gene attenuated cell proliferation. This attenuation is more notable in NCI-H446 cells following WA treatment. Overexpression of the AKR1C1 gene improved cell proliferation, and WA treatment partially reversed the anti-apoptotic effect of the AKR1C1 gene. Notably, the flow cytometry analysis and colony formation assay obtained the same results, that the knockdown of $\mathrm{AKR} 1 \mathrm{C} 1$ gene and WA treatment attenuated SCLC cells proliferation.
AKRICl attenuates SCLC tumor growth in vivo. To further confirm the growth-attenuating effect of WA and the growth-promotion effect of AKR1C1 on SCLC cells, a xenograft tumor growth assay was performed. Following 20 days, the tumors were harvested. The total weight of the WA treatment tumors was significantly lower in nude mice, compared with the control mice $(\mathrm{P}<0.05$, Fig. $6 \mathrm{~A})$. The subcutaneous tumor volume growth curve of NCI-H446 stably expressed in vivo was depicted in Fig. 6B. The tumor volume was significantly larger in the $\mathrm{OE}$ group nude mice, compared with the $\mathrm{NC}$ group mice at 5, 10, 15 and 20 days $(\mathrm{P}<0.05$, Fig. $6 \mathrm{~B})$; however, the tumor volume was reduced following WA treatment. Compared with the NC group, there was no significant weight loss observed in the WA treatment group animals ( $\mathrm{P}>0.05)$ (Fig. 6C). Immunohistochemistry of AKR1C1 antigen was detected, and results demonstrated expression of AKR1C1 was lower in the WA treatment group (Fig. 6E). The results revealed that WA could attenuate the 

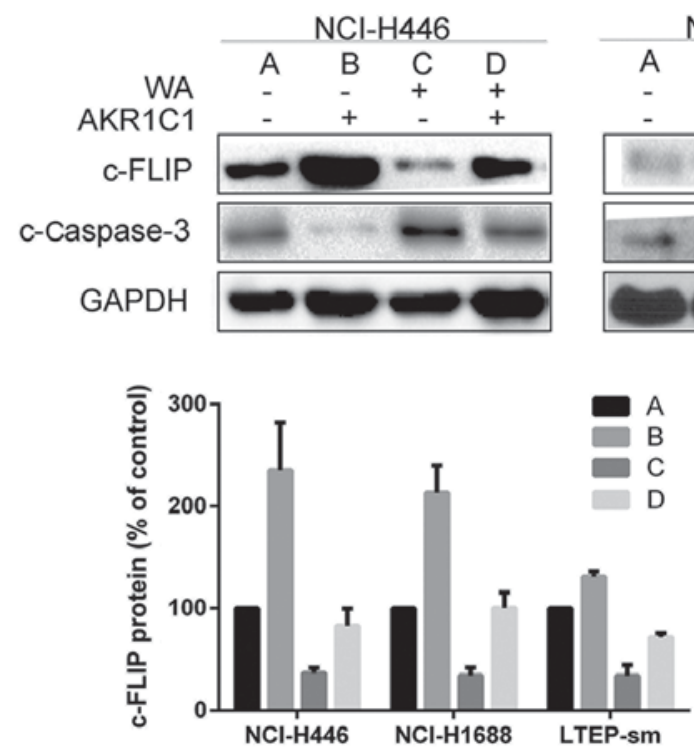
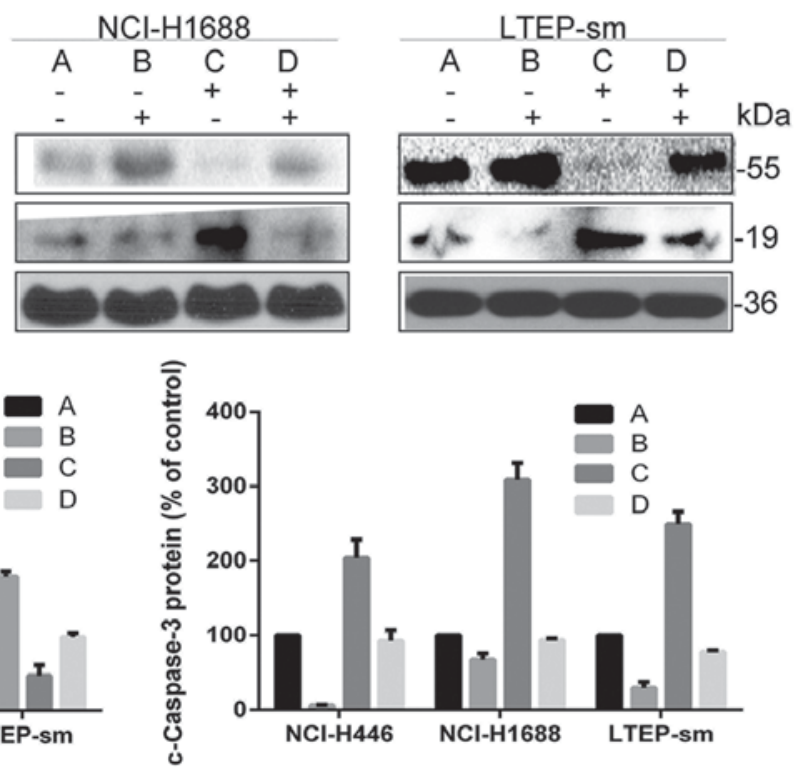

Figure 7. Overexpression of AKR1C1 gene reversed the pro-apoptotic function of WA via c-FLIP and c-Caspase-3. (A) Western blot analysis was used to analyze the expression of c-FLIP and c-Caspase-3. GAPDH was used as a reference. c-Caspase-3, cleaved-Caspase-3; c-FLIP, cleaved-Fas-associated death domain-like interleukin-1-converting enzyme-like inhibitory protein; AKR1C1, aldo-keto reductase family 1 member C1; WA, Wentilactone A.

expression of AKR1C1 and the proliferation of SCLC in vivo. These results provide further evidence that WA serves a tumor-attenuated role in SCLC.

Overexpression of AKRIC1 gene may partially reverse the pro-apoptotic function of WA via c-FLIP and c-Caspase-3. In the present study, it was demonstrated that overexpression of AKR1C1 gene promoted the expression of c-FLIP, whilst WA treatment inhibited the expression of the c-FLIP protein, activated c-Caspase-3 and induced apoptosis in SCLC cell lines (Fig. 7). Palackal et al (16) demonstrated that in patients with SCLC, differential display demonstrated that AKR1C transcripts are notably overexpressed. Wang et al (17) indicated that the downregulation of c-FLIP drove lung cancer cells into cellular apoptosis. c-FLIP had been demonstrated to induce apoptosis thus increasing Caspase- 8 and then Caspase- 3 activation (18).

$W A$ regulates the expression of $A K R I C 1$ protein via the IGF-1R/IRS1/PI3K/AKT/nuclear factor-erythroid 2associated factor 2 (Nrf2) signaling pathway. To further determine the mechanisms underlying the expression of AKR1C1 gene attenuation by WA, the investigation was focused on whether IGF-1R, IRS-1, PI3K, AKT and Nrf2 were associated with the WA-induced attenuated expression of AKR1C1 and pro-apoptotic factors. Together with their protein abundances, AKR1C1 was significantly reduced in the NCI-H446 cells following WA treatment $(\mathrm{P}<0.001)$, compared with control cells. AKR1C1 were significantly increased in the NCI-H446 cells following IGF-1 treatment. IGF-I, an activator of the IGF-IR pathway, promoted the expression of AKR1C1 and altered the cell apoptosis following WA treatment (Fig. 8A). It was determined that the IGF-1 reverses the biological effect of WA on SCLC cells. As depicted in Fig. 8B, together with their protein abundances, $\mathrm{p}-\mathrm{IGF}-1 \mathrm{R}(\mathrm{P}<0.001)$,
p-IRS-1( $<<0.001)$, p-PI3K $(\mathrm{P}<0.001)$, p-AKT $(\mathrm{P}<0.001)$, p-Nrf2 $(\mathrm{P}<0.001)$ and AKR1C1 $(\mathrm{P}<0.001)$ were significantly reduced in SCLC cells following WA treatment, compared with the control. The result revealed that the attenuation effect of WA on SCLC occurs at least partially by the targeting of AKR1C1 by the IGF-1R/IRS1/PI3K/AKT/Nrf2 signaling pathway. The study demonstrated that AKR1C1 may act as a potential target for the treatment of SCLC in the future.

\section{Discussion}

SCLC is characterized by rapid growth and early metastasis, which indicates strikingly high malignity and metastatic potential (1). The therapeutic potential of WA in SCLC treatment was highlighted (9).

A recent study demonstrated that WA significantly attenuated the growth of NCI-H446 cells, however the study did not fully alleviate the notable inhibitory effect of WA on other SCLC cell lines (9). In the present study, the notable inhibitory effect of WA was investigated in three SCLC cell lines NCI-H446, NCI-H1688 and LTEP-sm cells. Results of the CCK-8 assay, flow cytometry, scratch assay and western blot analysis indicated that WA had a notable effect on SCLC in vitro and in vivo. It was determined in the present study that WA inhibited c-FLIP in the three SCLC cell lines in a time-dependent manner, inducing apoptosis by upregulating c-Caspase-3, which was consistent with previous studies (19-23). However, the target gene of WA is not clear. The focus of the present study is the anti-SCLC mechanism of WA.

In the present study, bioinformatics analyses indicated that AKR1C1 was possibly the target gene in SCLC. Results of RT-qPCR and western blot confirmed AKR1C1 mRNA and protein levels were lower following WA treatment. Tian et al (24) demonstrated that high expression of AKR1C1 

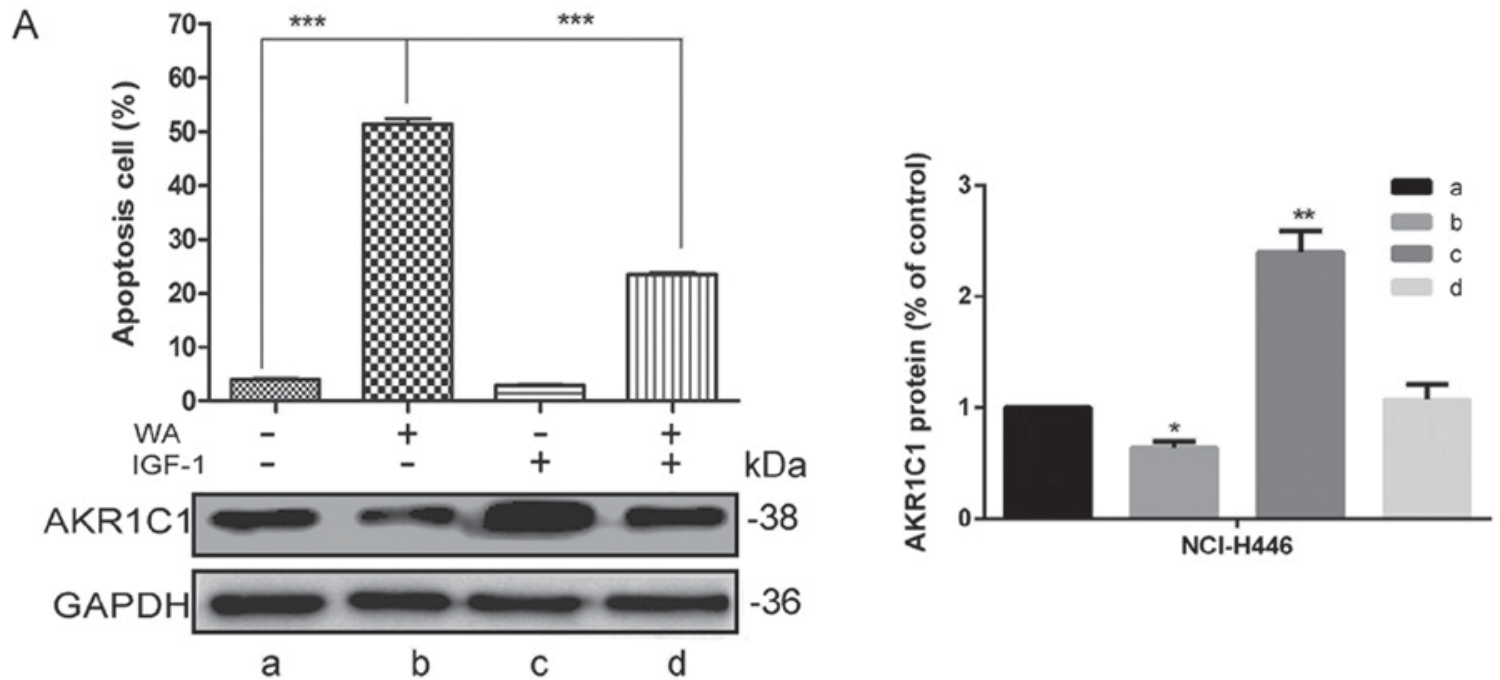

B
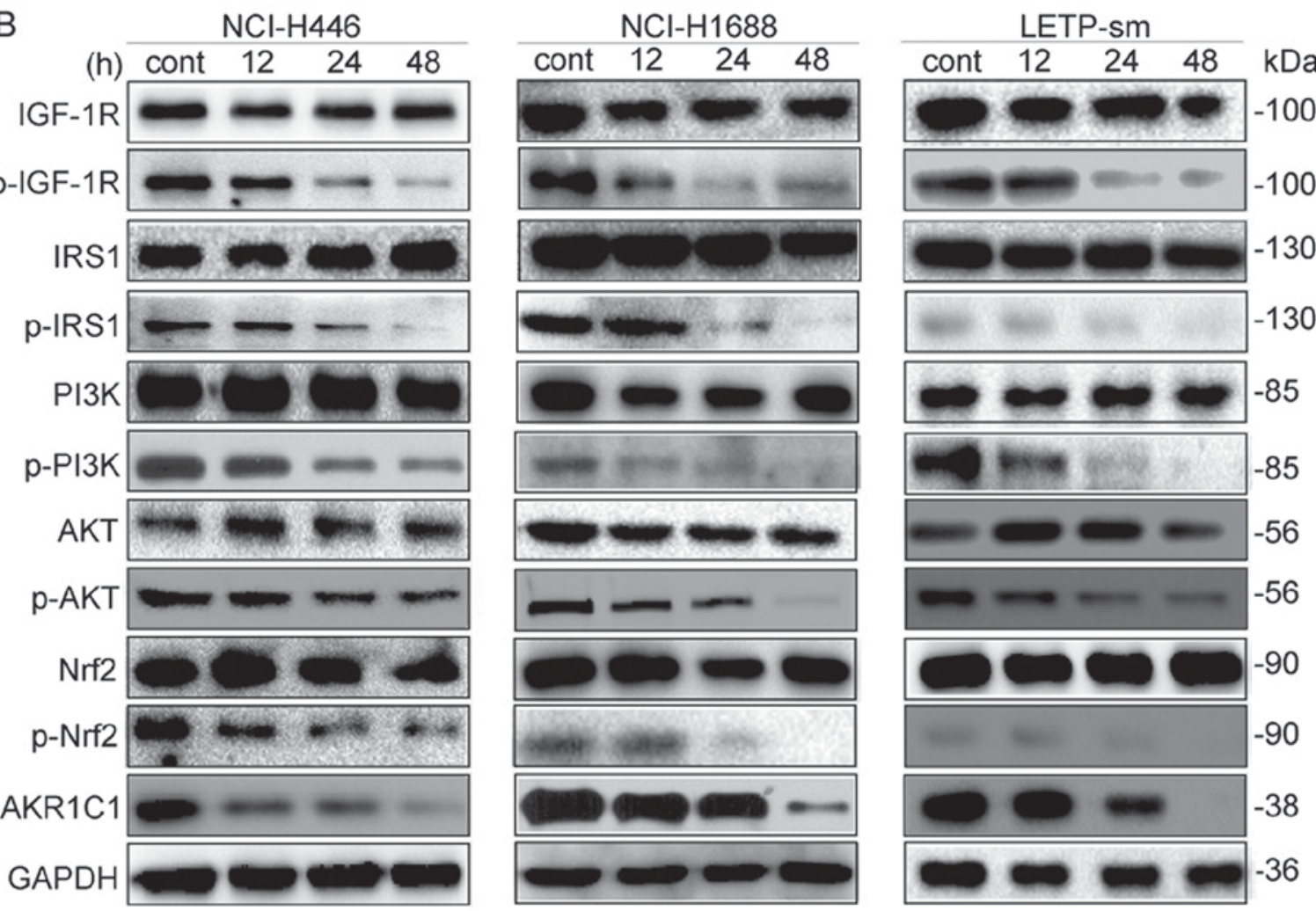

Figure 8. (A) Western blot analysis was used to analyze the expression of AKR1C1 protein prior to and following IGF-1 or WA treatment. The apoptosis cells were assessed using flow cytometry assay. (B) Associated-protein expression was measured by western blot analysis. ${ }^{*} \mathrm{P}<0.05$, ${ }^{* * *} \mathrm{P}<0.01$ and ${ }^{* * * *} \mathrm{P}<0.001 \mathrm{vs}$. a group. cont, 0 h; AKR1C1, aldo-keto reductase family 1 member C1; p-IGF-1R, phosphorylated-insulin like growth factor-1 receptor; WA, Wentilactone A; p-PI3K, phosphorylated-phosphoinositide 3-kinase; p-AKT, phosphorylated-AKT; p-Nrf2, phosphorylated-nuclear factor-erythroid 2-associated factor 2; p-IRS1, phosphorylated-insulin receptor substrate 1.

gene was associated with progression and poor prognosis of lung cancer. AKR1C1 is associated with numerous important biological processes, including the oxidation reduction and carcinogenesis of a number of vertebrate species (25). The effect and mechanism of AKR1C1 on SCLC remains unclear. According to previous studies, Nrf2 was a regulator of the AKR1C family (26-32). Yu et al (33) demonstrated that the PI3K-Akt pathway mediated the activation of NF-E2 associated factor-2 (Nrf2). Tao et al (34) demonstrated that IGF1R-mediated protection cells from apoptosis stopped upon the activation of PI3K. IGF1-R pathway was essential to mediate tumor cell survival and proliferation (35). IGF-1R overexpression increased cell survival and suppressed cell apoptosis (36). Further analysis on the association of WA treatment with AKR1C1 expression demonstrated that WA inhibited the expression of AKR1C1 via the IGF-1R/IRS-1/PI3K/AKT/Nrf2 signaling pathway by western blot analysis.

Further mechanism analysis indicated that WA inhibited the expression of $\mathrm{AKR} 1 \mathrm{C} 1$ and then induced the apoptosis of SCLC cells by the FLIP/Caspase-3 pathway. According to 
previous studies (21-23), apoptosis was known as a significant terminal pathway to remove infected cells. There are two central apoptosis pathways: The extrinsic pathway; and the intrinsic pathway (22). The key regulatory proteins in both pathways are Caspases (23). In addition, Caspases are classified as the initiator (Caspase-8 and -9) and effector of Caspase-3 (37). Wang et al (17) and Safa et al (18) demonstrated that c-FLIP was involved in chemotherapeutic drug resistance in numerous cancer cell types and anti-apoptotic in human NSCLC; however, c-FLIP has generally been demonstrated to act as a key negative regulator of apoptosis in human cancer cells, despite the identified dual functionality of c-FLIP as a pro- or anti-apoptotic factor in normal tissues. Enhanced expression of c-FLIP (long or short isoform) has been determined in various cancer types.

Apoptosis of SCLC cells were investigated by flow cytometry prior to and following WA treatment. Flow cytometry assay and western blot analysis both confirmed WA inhibited the expression of AKR1C1 via the IGF-1R/IRS-1/PI3K/AKT/Nrf2 signaling pathway and then inhibited c-FLIP and activated c-Caspase-3, which induced the apoptosis of SCLC cells. This research provided the experimental basis for the development of SCLC targeted drugs.

In summary, the present study revealed that WA induced the apoptosis by IGF-1R/IRS-1/PI3K/AKT/Nrf2/AKR1C1/ c-FLIP/c-Caspase-3. Most importantly, overexpression of AKR1C1 gene has pro-growth and anti-apoptosis effects on SCLC cells, which can be reversed by WA treatment. WA holds good promise as a novel potential AKR1C1 targeted drug candidate for future treatments of SCLC.

\section{Acknowledgements}

This authors thank the Laboratory of Marine Biology and Biotechnology, Qingdao National Laboratory for Marine Science and Technology, Key Laboratory of Experimental Marine Biology, Institute of Oceanology of the Chinese Academy of Sciences for their general support provided.

\section{Funding}

This present study was supported by the National Natural Science Foundation of China (grant nos., 41776140, 81473239 and 41576160).

\section{Availability of data and materials}

The datasets used and/or analyzed during the current study are available from the corresponding author on reasonable request.

\section{Authors' contributions}

WJ conceived and designed the experiments and was involved in the analysis and interpretation of data. BW performed the experiments. BJ contributed to the conception of the study and drafting the manuscript. $\mathrm{CH}$ contributed to the interpretation of results obtained. HW perform data analysis with constructive discussions and performed part of the experiments. LM contributed to reagents and performed part of the experiments. GX contributed to reagents and materials, and performed part of the experiments. CL contributed to analytical tools and performed part of the experiments. HT approved the final version and performed part of the experiments. RC was involved in drafting the manuscript and performed part of the experiments. All authors read and approved the final manuscript.

\section{Ethics approval and consent to participate}

All samples were obtained with the informed consent of the participants prior to their inclusion in the study, according to Helsinki Declaration principles and after approval of the ethics committee of Second Military Medical University.

\section{Patient consent for publication}

Not applicable.

\section{Competing interests}

The authors declare that they no competing interests.

\section{References}

1. Siegel RL, Miller KD and Jemal A: Cancer statistics, 2015. CA Cancer J Clin 65: 5-29, 2015.

2. Stinchcombe TE: Current treatments for surgically resectable, limited-stage, and extensive-stage small cell lung cancer. Oncologist 22: 1510-1517, 2017.

3. Mamdani H, Induru R and Jalal SI: Novel therapies in small cell lung cancer. Transl Lung Cancer Res 4: 533-544, 2015.

4. Liu B, Qin J and Zhou J: Advances in the treatment of relapsed small cell lung cancer. Zhongguo Fei Ai Za Zhi 20: 192-198, 2017 (In Chinese).

5. George J, Jing SL, Jang SJ, Cun Y, Ozretić L, Kong G, Leenders F, Lu X, Fernández-Cuesta L, Bosco G, et al: Comprehensive genomic profiles of small cell lung cancer. Nature 524: 47-53, 2015.

6. Calcabrini C, Catanzaro E, Bishayee A, Turrini E and Fimognari C: Marine sponge natural products with anticancer potential: An updated review. Mar Drugs 15: pii: E310, 2017.

7. Hussain $\mathrm{H}$ and Green IR: A patent review of the therapeutic potential of isoflavones (2012-2016). Expert Opin Ther Pat 27: 1135-1146, 2017.

8. Russo P, Nastrucci C and Cesario A: From the sea to anticancer therapy. Curr Med Chem 18: 3551-3562, 2011

9. Lv C, Hong Y, Miao L, Li C, Xu G, Wei S, Wang B, Huang C and Jiao B: Wentilactone $\mathrm{A}$ as a novel potential antitumor agent induces apoptosis and $\mathrm{G} 2 / \mathrm{M}$ arrest of human lung carcinoma cells, and is mediated by HRas-GTP accumulation to excessively activate the Ras/Raf/ERK/p53-p21 pathway. Cell Death Dis 4: e952, 2013

10. Sherlock G: Gene ontology: Tool for the unification of biology. Can Instit Food Sci Technol J 22: 415, 2009.

11. Ge QM, Huang CM, Zhu XY, Bian F and Pan SM: Differentially expressed miRNAs in sepsis-induced acute kidney injury target oxidative stress and mitochondrial dysfunction pathways. PLoS One 12: e0173292, 2017.

12. Wright GW and Simon RM: A random variance model for detection of differential gene expression in small microarray experiments. Bioinformatics 19: 2448-2455, 2003.

13. Yang H, Crawford N, Lukes L, Finney R, Lancaster M and Hunter KW: Metastasis predictive signature profiles pre-exist in normal tissues. Clin Exp Metastasis 22: 593-603, 2005.

14. Yin J, Shackel N, Zekry A, McGuinness PH, Richards C, Putten KV, McCaughan GW, Eris JM and Bishop GA: Real-time reverse transcriptase-polymerase chain reaction (RT-PCR) for measurement of cytokine and growth factor mRNA expression with fluorogenic probes or SYBR Green I. Immunol Cell Biol 79: 213-221, 2001.

15. Livak KJ and Schmittgen TD: Analysis of relative gene expression data using real-time quantitative PCR and the 2(-Delta Delta $\mathrm{C}(\mathrm{T})$ ) method. Methods 25: 402-408, 2001. 
16. Palackal NT, Lee SH, Harvey RG, Blair IA and Penning TM: Activation of polycyclic aromatic hydrocarbon trans-dihydrodiol proximate carcinogens by human aldo-keto reductase (AKR1C) enzymes and their functional overexpression in human lung carcinoma (A549) cells. J Biol Chem 277: 24799-24808, 2002.

17. Wang X, Chen W, Zeng W, Bai L, Tesfaigzi Y, Belinsky SA and Lin Y: Akt-mediated eminent expression of c-FLIP and Mcl-1 confers acquired resistance to TRAIL-induced cytotoxicity to lung cancer cells. Mol Cancer Ther 7: 1156-1163, 2008.

18. Safa AR and Pollok KE: Targeting the anti-apoptotic protein c-FLIP for cancer therapy.

19. Goldar S, Khaniani MS, Derakhshan SM and Baradaran B Molecular mechanisms of apoptosis and roles in cancer development and treatment. Asian Pac J Cancer Prev 16: 2129-2144, 2015

20. Sankari SL, Masthan KM, Babu NA, Bhattacharjee T and Elumalai M: Apoptosis in cancer-an update. Asian Pac J Cancer Prev 13: 4873-4878, 2012.

21. Elmore S: Apoptosis: A review of programmed cell death. Toxicol Pathol 35: 495-516, 2007.

22. Savitskaya MA and Onishchenko GE: Mechanisms of apoptosis. Biochemistry (Mosc) 80: 1393-1405, 2015.

23. Li J and Yuan J: Caspases in apoptosis and beyond. Oncogene 27: 6194-6206, 2008.

24. Tian H, Li X, Jiang W, Lv C, Sun W, Huang C and Chen R: High expression of AKR1C1 is associated with proliferation and migration of small-cell lung cancer cells. Lung Cancer (Auckl) 7: 53-61, 2016.

25. Penning TM: The aldo-keto reductases (AKRs): Overview. Chem Biol Interact 234: 236-246, 2015.

26. Kobayashi A, Kang MI, Okawa H, Ohtsuji M, Zenke Y, Chiba T, Igarashi $\mathrm{K}$ and Yamamoto M: Oxidative stress sensor Keap1 functions as an adaptor for Cul3-based E3 ligase to regulate proteasomal degradation of Nrf2. Mol Cell Biol 24: 7130-7139, 2004.

27. Jaiswal AK: Nrf2 signaling in coordinated activation of antioxidant gene expression. Free Radic Biol Med 36: 1199-1207, 2004

28. Homma S, Ishii Y, Morishima Y, Yamadori T, Matsuno Y, Haraguchi N, Kikuchi N, Satoh H, Sakamoto T, Hizawa N, et al: Nrf2 enhances cell proliferation and resistance to anticancer drugs in human lung cancer. Clin Cancer Res 15: 3423-3432, 2009.
29. Kaspar JW, Niture SK and Jaiswal AK: Nrf2:INrf2 (Keap1) signaling in oxidative stress. Free Radic Biol Med 47: 1304-1309, 2009.

30. Nguyen T, Yang CS and Pickett CB: The pathways and molecular mechanisms regulating Nrf2 activation in response to chemical stress. Free Radic Biol Med 37: 433-441, 2004.

31. de Vries HE, Witte M, Hondius D, Rozemuller AJ, Drukarch B, Hoozemans $\mathbf{J}$ and van Horssen J: Nrf2-induced antioxidant protection: A promising target to counteract ROS-mediated damage in neurodegenerative disease? Free Radic Biol Med 45: 1375-1383, 2008.

32. Zenkov NK, Menshchikova EB and Tkachev VO: Keap1/Nrf2/ARE redox-sensitive signaling system as a pharmacological target. Biochemistry (Mosc) 78: 19-36, 2013.

33. Yu JB, Shi J, Zhang Y, Gong LR, Dong SA, Cao XS, Wu LL and Wu LN: Electroacupuncture ameliorates acute renal injury in lipopolysaccharide-stimulated rabbits via induction of HO-1 through the PI3K/Akt/Nrf2 pathways. PLoS One 10: e0141622, 2015.

34. Tao Y, Pinzi V, Bourhis J and Deutsch E: Mechanisms of disease: Signaling of the insulin-like growth factor 1 receptor pathway-therapeutic perspectives in cancer. Nat Clin Pract Oncol 4: 591-602, 2007.

35. Nurwidya F, Andarini S, Takahashi F, Syahruddin E and Takahashi K: Implications of insulin-like growth factor 1 receptor activation in lung cancer. Malays J Med Sci 23: 9-21, 2016.

36. Tao Y1,Pinzi V, Bourhis J, and DeutschE: Expression and distribution of insulin-like growth factor-1 receptor pathway-therapeutic perspectives in cancer. Nat Clin Pract Oncol 4: 591-602, 2007.

37. Yi CH and Yuan AJ: The Jekyll and Hyde functions of caspases. Dev Cell 16: 21-34, 2009

This work is licensed under a Creative Commons Attribution-NonCommercial-NoDerivatives 4.0 International (CC BY-NC-ND 4.0) License. 